\title{
Role of mitochondrial ATP-sensitive potassium channel-mediated PKC- $\varepsilon$ in delayed protection against myocardial ischemia/reperfusion injury in isolated hearts of sevoflurane-preconditioned rats
}

\author{
C. Wang ${ }^{1,2 *}$, S.M. $\mathrm{Hu}^{2 *}$, H. Xie ${ }^{1}$, S.G. Qiao ${ }^{1}, \mathrm{H} . \mathrm{Liu}^{3}$ and C.F. $\mathrm{Liu}^{2}$ \\ ${ }^{1}$ Department of Anesthesiology and Critical Care, The Second Affiliate Hospital, Soochow University, Suzhou, China \\ ${ }^{2}$ Institute of Neuroscience, Soochow University, Suzhou, China \\ ${ }^{3}$ Department of Anesthesiology and Pain Medicine, University of California Davis Health System, Davis, CA, USA
}

\begin{abstract}
This study aimed to determine the role of mitochondrial adenosine triphosphate-sensitive potassium (mitoK $\mathrm{ATP}_{\text {) }}$ channels and protein kinase $C(\mathrm{PKC})-\varepsilon$ in the delayed protective effects of sevoflurane preconditioning using Langendorff isolated heart perfusion models. Fifty-four isolated perfused rat hearts were randomly divided into 6 groups $(n=9)$. The rats were exposed for $60 \mathrm{~min}$ to $2.5 \%$ sevoflurane (the second window of protection group, SWOP group) or 33\% oxygen inhalation (I/R group) $24 \mathrm{~h}$ before coronary occlusion. The control group (CON) and the sevoflurane group (SEVO) group were exposed to $33 \%$ oxygen and $2.5 \%$ sevoflurane for $60 \mathrm{~min}$, respectively, without coronary occlusion. The mitoK $\mathrm{ATP}$ channel inhibitor 5-hydroxydecanoate (5-HD) was given 30 min before sevoflurane preconditioning (5-HD + SWOP group). Cardiac function indices, infarct sizes, serum cardiac troponin I (cTnl) concentrations, and the expression levels of phosphorylated PKC- $\varepsilon$ (p-PKC- $\varepsilon$ ) and caspase- 8 were measured. Cardiac function was unchanged, $p-P K C-\varepsilon$ expression was upregulated, caspase-8 expression was downregulated, cTnl concentrations were decreased, and the infarcts were significantly smaller $(P<0.05)$ in the SWOP group compared with the I/R group. Cardiac function was worse, $\mathrm{p}-\mathrm{PKC}-\varepsilon$ expression was downregulated, caspase- 8 expression was upregulated, cTnl concentration was increased and infarcts were larger in the 5-HD + SWOP group $(P<0.05)$ compared with

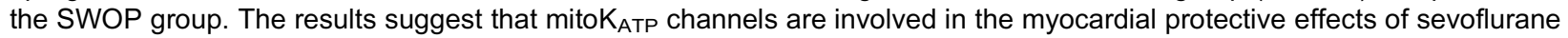
in preconditioning against I/R injury, by regulating $\mathrm{PKC}-\varepsilon$ phosphorylation before ischemia, and by downregulating caspase-8 during reperfusion.
\end{abstract}

Key words: Ischemia; Reperfusion; mitoK $_{\text {atp }}$ channel; Preconditioning; Protein kinase C

\section{Introduction}

Myocardial ischemia/reperfusion (I/R) injury occurs not only in coronary heart disease but also as a complication of cardiac surgery performed to treat lethal reperfusion injury, myocardial stunning, reperfusion arrhythmias, and vascular injury. $\mathrm{I} / \mathrm{R}$ injury is a significant factor in perioperative complications and increased mortality (1). Therefore, preventing myocardial $\mathrm{I} / \mathrm{R}$ injury in noncardiac surgery patients and nonsurgical cardiac ischemia may decrease the incidence of cardiac complications.

Repeated short episodes of myocardial ischemia, called myocardial ischemic preconditioning (IPC), reduce the occurrence of myocardial I/R injury (2). However, ischemic pretreatment is difficult to implement clinically. Anesthetic preconditioning (APC) with inhaled anesthetics that are widely used in clinical anesthesia was first reported in 1997 to protect the myocardium from I/R injury (3). Since then, numerous studies have shown that inhaled anesthetics simulate ischemic preconditioning to reduce myocardial $\mathrm{I} / \mathrm{R}$ injury, which has clinically significant implications (4-6). APC lowers the risk of myocardial ischemia, is readily available, and is convenient to apply, making it a good alternative to ischemic

Correspondence: Hong Xie: <xiehdoc@126.com>.

${ }^{*}$ C. Wang and S.M. Hu are co-first authors who contributed equally to this study.

Received January 27, 2014. Accepted October 7, 2014. First published online March 27, 2015. 
drugs and methods. APC is especially suitable for preoperative inhalational anesthetic pretreatment for myocardial I/R injury. Inhalational anesthetic pretreatment may trigger the release of a variety of endogenous bioactive substances in myocardial or brain tissue through cell membrane receptor binding or through direct activation of intracellular signaling pathways involving a variety of cell types and protective substances. Although numerous studies have focused on APC, its specific mechanism of action has not yet been fully elucidated (7). This study focused on the mechanism underlying the protective effect of APC.

Opening of mitochondrial ATP-sensitive potassium (mitoK $\mathrm{K}_{\text {ATP }}$ ) channels plays an important role in protecting against myocardial ischemic disease (8) and is known to occur during APC $(9,10)$. Recent studies have found that mitoK $_{\text {ATP }}$ channels are involved in the mitochondrial membrane cascade-signaling pathway during myocardial ischemic preconditioning (11). The mitoK specific blocker 5-hydroxydecanoate (5-HD) blocks the myocardial protective effect of ischemic and pharmacological preconditioning $(12,13)$. Pretreating nerve cells with diazoxide, a selective opener of mitoK $\mathrm{K}_{\text {ATP }}$ channels, induces

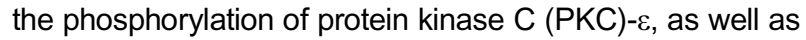
the opening of mitoK $\mathrm{K}_{\mathrm{ATP}}$ channels, thereby forming a system of positive feedback regulation (14). A recent study of the effects of theaflavins revealed that cardiac muscle contractility depends on PKC- $\varepsilon$ concentration (15).

The delayed protective effects of sevoflurane preconditioning can effectively limit peri- and post-operative complications of cardiac surgery. This study utilized the Langendorff isolated heart perfusion model to investigate the effects of mitoK $\mathrm{ATP}_{\mathrm{P}}$ channel-mediated PKC- $\varepsilon$ in relation to the delayed protective effects of sevoflurane preconditioning.

\section{Material and Methods}

\section{Animals}

The Committee of the Medical College of Soochow University (Suzhou, China; License No. 20020008, Grade II) approved the use of healthy clean-grade male Sprague-Dawley (SD) rats that were maintained in their Experimental Animal Center for this study.

\section{Experimental protocol}

The Committee for Experimental Animals of the Medical College of Soochow University, Suzhou, China (Chairperson, Professor Zhi-mou Xue; No. SZULL20090309) approved the study protocol on March 9, 2009.

A total of 54 rats were randomly assigned to 6 groups ( $n=9 /$ group): Rats given $33 \%$ oxygen or $2.5 \%$ sevoflurane for 60 min without occlusion and reperfusion $24 \mathrm{~h}$ later served as the control (CON) and sevoflurane (SEVO) groups, respectively. Rats in the I/R group were given $33 \%$ oxygen for $60 \mathrm{~min}$ followed by a $30 \mathrm{~min}$ equilibration period, $30 \mathrm{~min}$ of occlusion, and $2 \mathrm{~h}$ of reperfusion $24 \mathrm{~h}$ later. Rats in the SWOP (second window of protection) group were given $2.5 \%$ sevoflurane for $60 \mathrm{~min}$ followed by a $30 \mathrm{~min}$ equilibration period, $30 \mathrm{~min}$ of occlusion, and $2 \mathrm{~h}$ of reperfusion $24 \mathrm{~h}$ later. Rats in the 5-HD + SWOP group were given an intraperitoneal injection of $10 \mathrm{mg} / \mathrm{kg} \mathrm{5-HD} \mathrm{(a}$ selective mitoKATP channel antagonist; H135, Sigma, USA) $30 \mathrm{~min}$ before inhalation of $2.5 \%$ sevoflurane, followed by a $30 \mathrm{~min}$ equilibration period, $30 \mathrm{~min}$ of occlusion, and $2 \mathrm{~h}$ of reperfusion $24 \mathrm{~h}$ later. Rats in the 5-HD group were given an intraperitoneal injection of $10 \mathrm{mg} / \mathrm{kg}$ 5-hydroxydecanoate without inhalation of sevoflurane followed by a 30 min equilibration period, $30 \mathrm{~min}$ of occlusion, and $2 \mathrm{~h}$ of reperfusion $24 \mathrm{~h}$ later. The CON and SEVO groups did not undergo occlusion and reperfusion. The I/R, SWOP, 5-HD + SWOP, and 5-HD groups underwent occlusion and reperfusion.

Cardiac function indices of the rats in all groups were recorded. Myocardial infarct size was measured by triphenyl tetrazolium chloride (TTC) staining. Cardiac troponin I (cTnl) concentration in the coronary transudate was measured by an enzyme-linked immunosorbent assay (ELISA). The expression levels of phosphorylated PKC- $\varepsilon$ (p-PKC- $\varepsilon$ ) and caspase- 8 were assayed by Western blot. Rats that developed $\mathrm{CO}_{2}$ accumulation during sevoflurane preconditioning, refractory ventricular fibrillation, frequent recurrent arrhythmia, left ventricle systolic pressure (LVSP) $<80 \mathrm{mmHg}$, or heart rate (HR) $<200 \mathrm{bpm}$ were excluded from the experiment.

\section{Sevoflurane preconditioning}

Rats were placed in a glass box connected to the gas flow inlet of a Sevotec 5 sevoflurane vaporizer (Drager Vapor 2000, Drager Medical, Germany) (16). The box was continuously infused with $2.5 \%$ sevoflurane (h20090714, Abbott Pharmaceutical, China) and 97.5\% oxygen at a flow of $2 \mathrm{~L} / \mathrm{min}$. An anesthesia monitor (ULT-I type, Datex-Ohmeda, USA) was connected to monitor the concentrations of sevoflurane, $\mathrm{O}_{2}$, and $\mathrm{CO}_{2}$. The rats were placed in the glass box for $1 \mathrm{~h}$ after the sevoflurane concentration had reached approximately 1.0 MAC (monitored anesthesia care), after which they were returned to their cages and fed a normal diet.

\section{Langendorff isolated heart perfusion model}

Krebs-Henseleit $(\mathrm{K}-\mathrm{H})$ solution, consisting of $118.0 \mathrm{mM} \mathrm{NaCl}, 4.8 \mathrm{mM} \mathrm{KCl}, 1.2 \mathrm{mM} \mathrm{KH} \mathrm{KSO}_{4}$, $25.0 \mathrm{mM} \mathrm{NaHCO}_{3}, 1.2 \mathrm{mM} \mathrm{MgSO}_{4}, 2.5 \mathrm{mM} \mathrm{CaCl}_{2}$, and $11.0 \mathrm{mM}$ glucose was prepared. The $\mathrm{pH}$ was adjusted to $7.35-7.45$, and the mixture was heated to $36.0^{\circ} \mathrm{C}$ on a temperature-controlled mechanical stirrer (90-3 type, Huxi Analysis Instrument, China). A pre-access test was conducted for $30 \mathrm{~min}$ to ensure that the $95 \% \quad \mathrm{O}_{2}$ and $5 \% \mathrm{CO}_{2}$ gas was fully mixed with the $\mathrm{K}-\mathrm{H}$ solution. $\mathrm{A}$ temperature-controlled water bath (ZC-10, Alcott Biotechnology Co., Ltd., China) was used to maintain 
the external circulation temperature at $36^{\circ} \mathrm{C}$. The rats were intraperitoneally anesthetized with $50 \mathrm{mg} / \mathrm{kg}$ pentobarbital sodium (060928, Haitai Riel Biotechnology, China), followed by $500 \mathrm{U} / \mathrm{kg}$ of heparin. The rat hearts were quickly excised and mounted on a Langendorff apparatus via the aorta for retrograde perfusion with the $\mathrm{K}-\mathrm{H}$ solution at a constant pressure of $10 \mathrm{kPa}$. The aorta of the hearts was tied with 5-0 silk to produce global ischemia. (17). The pump was adjusted to maintain a coronary flow rate of $12 \mathrm{~mL} / \mathrm{min}$. A cuff pressure transducer (YP200, SIA Industrial and Trade, China) was inserted into the left ventricle to monitor heart function. The cuff volume was adjusted to maintain a stable left ventricular end diastolic pressure (LVEDP) of 6-10 $\mathrm{mmHg}$ during initial equilibration.

\section{Cardiac function}

Cardiac function indices including LVSP, LVEDP, the maximal rate of rise of ventricular pressure $\left( \pm \mathrm{dP} / \mathrm{dt}_{\max }\right)$, and HR were monitored after 30 min of equilibration $\left(T_{0}\right)$, and then at $30\left(T_{1}\right), 60\left(T_{2}\right), 90\left(T_{3}\right)$, and $120 \mathrm{~min}\left(T_{4}\right)$ after reperfusion using the Med Lab 6.0 software on a $\mathrm{U} / 4 \mathrm{C} 501 \mathrm{H}$ Med Lab biological signal acquisition and processing system (Mei Yi Technology, China).

\section{Infarct size determination and cardiac troponin I}

After $2 \mathrm{~h}$ of reperfusion, the heart was removed and cooled at $-80^{\circ} \mathrm{C}$ for $5 \mathrm{~min}$. The heart was then cut into 6 cross-sectional slices of $2-\mathrm{mm}$ thickness that were incubated at $37^{\circ} \mathrm{C}$ for $15 \mathrm{~min}$ in $1 \%$ TTC (T8877, Sigma) in $0.1 \mathrm{M}$ phosphate buffer, $\mathrm{pH} 7.4$ and fixed overnight in $10 \%$ formaldehyde. The infarct size is reported as a percentage of the total range of the left ventricle area at risk (AAR) using the Alpha View gel image analysis software (Alpha Ease FC, USA). Coronary transudate $(2 \mathrm{~mL}$ ) was collected at $\mathrm{T}_{0}$ and $\mathrm{T}_{4}$, and centrifuged for $15 \mathrm{~min}$ at $1800 \mathrm{~g}$ and $4^{\circ} \mathrm{C}$. cTnl concentrations in the coronary transudate were detected using cTnl ELISA kits (Xitang Biotechnology Company, China).

\section{Protein extraction and Western blot analysis}

The hearts were kept frozen at $-80^{\circ} \mathrm{C}$ in liquid nitrogen until analysis. Lysis buffer and phosphatase inhibitorextracted proteins were added, and the tissues were homogenized by low-temperature cracking using ultrasonication. The protein content of the samples was determined using a bicinchoninic acid assay kit (P0010, Biyuntian Biotechnology Company, China) and the protein content of the lysate was adjusted to the same concentration. The lysates were heated for $5 \mathrm{~min}$ in a $97^{\circ} \mathrm{C}$ water bath and $20 \mu \mathrm{g}$ of each sample was electrophoresed in $12 \%$ polyacrylamide gels (Bio-Rad, USA) to isolate the proteins, which were then transferred onto nitrocellulose membranes (Millipore Company, USA). The proteins were blocked with $5 \%$ skim milk for $2 \mathrm{~h}$. The samples were incubated overnight at $4^{\circ} \mathrm{C}$ with anti-p-PKC- $\varepsilon$ (1:1000; ab63387, Abcam, USA) and anti-caspase-8 (1:1000; D35G2, Santa Cruz, USA) antibodies, with glyceraldehyde-3-phosphate dehydrogenase (GAPDH, 1:1000; AG019, Biyuntian Biotechnology Company, China) as the internal reference. The membranes were rinsed three times with Tris-buffered saline containing Tween-20 and incubated with secondary antibodies for $2 \mathrm{~h}$. An enhanced luminol-based chemoluminescence kit (34077, Thermo, USA) was used for secondary staining. The stained nitrocellulose membranes were placed into the lightemitting reagent solution (Western blot chemiluminescence reagent $A B$ solution, $0609^{*} 025$, Merck, Germany) and transferred to a dark room. Membranes were read by an automatic processor for color development and fixing. p-PKC- $\varepsilon$ and caspase- 8 expression are reported as gray density relative to that of GAPDH.

\section{Statistical analysis}

The Graph Pad Prism 4.00 statistical software was used for statistical processing. Data are reported as means $\pm S D$. The hemodynamic data were analyzed using analysis of variance (ANOVA) for repeated measures and one-way ANOVA followed by the Tukey multiple-comparison test to compare the differences among groups. $\mathrm{P}<0.05$ was considered to be statistically significant.

\section{Results}

Rats with $\mathrm{CO}_{2}$ accumulation during sevoflurane preconditioning and those that developed refractory ventricular fibrillation, recurrent arrhythmia, LVSP $<80 \mathrm{mmHg}, \mathrm{HR}<200 \mathrm{bpm}$ after $30 \mathrm{~min}$ of equilibration were excluded from the experiment.

\section{Cardiac function}

LVSP, HR, and $\pm \mathrm{dP} / \mathrm{dtmax}$ decreased and LVEDP significantly increased in each group during reperfusion $(\mathrm{P}<0.05)$, compared with the levels during equilibration (Table 1). LVSP, HR, and $\pm \mathrm{dP} / \mathrm{dtmax}$ increased and LVEDP significantly decreased in the SWOP group $(P<0.05)$, compared with those in the I/R group. LVSP, $\mathrm{HR}$, and $\pm \mathrm{dP} / \mathrm{dtmax}$ significantly decreased, whereas the LVEDP significantly increased in the $5-\mathrm{HD}+$ SWOP group $(P<0.05)$, compared with those in the SWOP group. The preconditioning effects induced by sevoflurane were abolished by $5-\mathrm{HD}(\mathrm{P}<0.05)$ and $5-\mathrm{HD}$ alone did not influence LVDP during reperfusion compared with its effect in the $\mathrm{I} / \mathrm{R}$ group $(\mathrm{P}>0.05)$.

\section{Myocardial infarct size}

The myocardial infarcts in the SWOP group $(25 \pm 4 \%)$ were smaller $(P<0.05)$ than those in the $1 / R$ group $(42 \pm 5 \%)$. The myocardial infarcts in the $5-\mathrm{HD}+\mathrm{SWOP}$ group $(37 \pm 3 \%)$ were smaller $(P<0.05)$ than those in the I/R group $(42 \pm 5 \%)$, indicating that $5-\mathrm{HD}$ negated the effects of sevoflurane. However, 5-HD itself did not 
Table 1. Hemodynamic parameters.

\begin{tabular}{|c|c|c|c|c|c|}
\hline & \multirow[t]{2}{*}{ Baseline $\left(T_{0}\right)$} & \multicolumn{4}{|c|}{ Reperfusion } \\
\hline & & $30 \min \left(T_{1}\right)$ & $60 \min \left(T_{2}\right)$ & $90 \min \left(T_{3}\right)$ & $120 \min \left(T_{4}\right)$ \\
\hline \multicolumn{6}{|l|}{$\operatorname{HR}\left(\min ^{-1}\right)$} \\
\hline $\mathrm{CON}$ & $263 \pm 25$ & $256 \pm 28$ & $249 \pm 24$ & $230 \pm 29$ & $224 \pm 21$ \\
\hline $\mathrm{I} / \mathrm{R}$ & $272 \pm 34$ & $223 \pm 18^{*}$ & $212 \pm 14^{*}$ & $198 \pm 19^{*}$ & $186 \pm 21^{*}$ \\
\hline SEVO & $257 \pm 29$ & $254 \pm 26^{\#}$ & $248 \pm 25^{\#}$ & $235 \pm 24^{\#}$ & $223 \pm 32^{\star \#}$ \\
\hline SWOP & $255 \pm 22$ & $240 \pm 25^{\star \#}$ & $241 \pm 19^{\star \#}$ & $233 \pm 20^{* \#}$ & $219 \pm 30^{\star \#}$ \\
\hline $5-\mathrm{HD}+\mathrm{SWOP}$ & $261 \pm 28$ & $228 \pm 18^{*+}$ & $218 \pm 16^{*+}$ & $190 \pm 18^{*+}$ & $187 \pm 17^{*+}$ \\
\hline $5-\mathrm{HD}$ & $275 \pm 30$ & $225 \pm 21^{*+}$ & $219 \pm 18^{*+}$ & $191 \pm 25^{*+}$ & $186 \pm 19^{*+}$ \\
\hline \multicolumn{6}{|l|}{ LVSP (mmHg) } \\
\hline CON & $119 \pm 13$ & $111 \pm 12$ & $90 \pm 8$ & $82 \pm 7$ & $79 \pm 6$ \\
\hline $\mathrm{I} / \mathrm{R}$ & $117 \pm 15$ & $79 \pm 9^{*}$ & $64 \pm 9^{*}$ & $57 \pm 7^{*}$ & $47 \pm 7^{*}$ \\
\hline SEVO & $125 \pm 11$ & $100 \pm 12^{\star \#}$ & $89 \pm 10^{\star \#}$ & $79 \pm 9^{\star \#}$ & $65 \pm 11^{* \#}$ \\
\hline SWOP & $115 \pm 13$ & $104 \pm 10^{\star \#}$ & $87 \pm 8^{\star \#}$ & $77 \pm 11^{\star \#}$ & $64 \pm 10^{\star \#}$ \\
\hline $5-\mathrm{HD}+\mathrm{SWOP}$ & $114 \pm 14$ & $82 \pm 11^{*+}$ & $72 \pm 9^{*+}$ & $66 \pm 9^{*+}$ & $54 \pm 6^{*+}$ \\
\hline $5-\mathrm{HD}$ & $117 \pm 16$ & $78 \pm 10^{\star+}$ & $71 \pm 11^{*+}$ & $65 \pm 12^{*+}$ & $56 \pm 9^{*+}$ \\
\hline \multicolumn{6}{|l|}{ LVEDP $(\mathrm{mmHg})$} \\
\hline CON & $6.4 \pm 1.3$ & $10.6 \pm 7.6^{*}$ & $12.8 \pm 9.7^{*}$ & $15.5 \pm 7.9^{*}$ & $17.2 \pm 12.2^{*}$ \\
\hline $\mathrm{l} / \mathrm{R}$ & $6.3 \pm 1.5$ & $45.8 \pm 9.6^{*}$ & $41.5 \pm 11.7^{*}$ & $39.6 \pm 9.1^{*}$ & $38.1 \pm 14.2^{*}$ \\
\hline SEVO & $5.9 \pm 0.9$ & $11.2 \pm 8.9^{\star \#}$ & $13.4 \pm 6.8^{* \#}$ & $15.3 \pm 8.8^{\star \#}$ & $16.2 \pm 13.5^{\star \#}$ \\
\hline SWOP & $6.9 \pm 1.1$ & $25.1 \pm 5.9^{\star \#}$ & $21.8 \pm 6.9^{\star \#}$ & $18.1 \pm 5.3^{\star \#}$ & $15.9 \pm 12.2^{\star \#}$ \\
\hline $5-\mathrm{HD}+\mathrm{SWOP}$ & $6.1 \pm 1.0$ & $48.1 \pm 7.0^{*+}$ & $41.8 \pm 7.0^{*+}$ & $39.0 \pm 5.2^{*+}$ & $36.2 \pm 11.8^{*+}$ \\
\hline $5-\mathrm{HD}$ & $6.7 \pm 1.6$ & $47.8 \pm 8.6^{*+}$ & $41.6 \pm 12.7^{*+}$ & $37.9 \pm 6.6^{*+}$ & $35.1 \pm 14.7^{*+}$ \\
\hline \multicolumn{6}{|c|}{$+\mathrm{dp} / \mathrm{dtmax}(\mathrm{mmHg} / \mathrm{s})$} \\
\hline CON & $3892 \pm 184$ & $2765 \pm 159^{*}$ & $2532 \pm 132^{*}$ & $2214 \pm 140^{*}$ & $1897 \pm 134^{*}$ \\
\hline $\mathrm{l} / \mathrm{R}$ & $3780 \pm 196$ & $1855 \pm 152^{*}$ & $1199 \pm 115^{*}$ & $893 \pm 111^{*}$ & $763 \pm 118^{*}$ \\
\hline SEVO & $3762 \pm 164$ & $2876 \pm 127^{\star \#}$ & $2568 \pm 152^{\star \#}$ & $2342 \pm 130^{\star \#}$ & $1955 \pm 124^{\star \#}$ \\
\hline SWOP & $3802 \pm 164$ & $2755 \pm 139^{\star \#}$ & $1646 \pm 241^{* \#}$ & $1393 \pm 229^{\star \#}$ & $840 \pm 229^{* \#}$ \\
\hline $5-\mathrm{HD}+\mathrm{SWOP}$ & $3681 \pm 186$ & $1875 \pm 132^{*+}$ & $1399 \pm 105^{\star+}$ & $949 \pm 120^{*+}$ & $897 \pm 108^{*+}$ \\
\hline $5-\mathrm{HD}$ & $3826 \pm 221$ & $1808 \pm 134^{*+}$ & $1382 \pm 146^{*+}$ & $943 \pm 89^{*+}$ & $890 \pm 70^{*+}$ \\
\hline \multicolumn{6}{|c|}{$-\mathrm{dp} / \mathrm{dtmax}(\mathrm{mmHg} / \mathrm{s})$} \\
\hline CON & $2907 \pm 199$ & $2853 \pm 120^{*}$ & $2758 \pm 135^{*}$ & $2770 \pm 114^{*}$ & $2781 \pm 119^{*}$ \\
\hline $\mathrm{l} / \mathrm{R}$ & $2721 \pm 268$ & $1009 \pm 110^{*}$ & $771 \pm 120^{\star}$ & $599 \pm 104^{*}$ & $512 \pm 109^{*}$ \\
\hline SEVO & $2877 \pm 189$ & $2793 \pm 124^{\star \#}$ & $2678 \pm 124^{\star \#}$ & $2570 \pm 138^{\#}$ & $2481 \pm 129^{* \#}$ \\
\hline SWOP & $2807 \pm 193$ & $1282 \pm 111^{* \#}$ & $1089 \pm 132^{\star \#}$ & $948 \pm 173^{\star \#}$ & $696 \pm 159^{\star \#}$ \\
\hline $5-\mathrm{HD}+\mathrm{SWOP}$ & $2648 \pm 168$ & $1106 \pm 147^{*+}$ & $996 \pm 165^{\star+}$ & $772 \pm 129^{*+}$ & $521 \pm 144^{*+}$ \\
\hline $5-\mathrm{HD}$ & $2820 \pm 173$ & $1059 \pm 162^{*+}$ & $785 \pm 101^{*+}$ & $749 \pm 136^{*+}$ & $510 \pm 135^{*+}$ \\
\hline
\end{tabular}

Data are reported as means $\pm S D\left(n=9 /\right.$ group). ${ }^{*}<<0.05$ vs T0; ${ }^{\#} \mathrm{P}<0.05$ vs $\mathrm{l} / \mathrm{R}$ group; ${ }^{+} \mathrm{P}<0.05$ vs SWOP group (one-way ANOVA). HR: heart rate; LVSP: left ventricular peak pressure; LVEDP: left ventricular end diastolic pressure; +dp/dtmax: maximum rate of rise of left ventricular pressure; -dp/dtmax: maximum descending rate of left ventricular pressure; CON: control; I/R: ischemia/reperfusion; SEVO: sevoflurane; SWOP: second window of protection; 5-HD: 5-hydroxydecanoate.

influence the myocardial infarct size compared with the $\mathrm{I} / \mathrm{R}$ group $(\mathrm{P}>0.05)$. The differences in size among the other groups were not statistically significant $(P>0.05)$. The results are shown in Figure 1.

\section{Concentration of cTnl}

The cTnl concentration in coronary transudate was higher in the $\mathrm{I} R(892 \pm 27)$, SWOP $(617 \pm 29)$, and 5HD + SWOP groups $(837 \pm 26)$ than in the CON group $(498 \pm 26)$. The cTnl concentration in the coronary transudate from the $\mathrm{I} / \mathrm{R}$ group $(892 \pm 27)$ was higher than that in the SWOP $(617 \pm 29)$ and in the SEVO groups $(501 \pm 23 ; \mathrm{P}<0.05)$. The $\mathrm{cTnl}$ concentration in the coronary transudate from the $5-\mathrm{HD}+\mathrm{SWOP}$ group $(837 \pm 26)$ was higher $(P<0.05)$ than that in the SWOP group $(617 \pm 29)$, indicating that $5-\mathrm{HD}$ negated the effects of sevoflurane; however, 5-HD alone did not influence the coronary transudate cTnl concentration compared with the $1 / R$ group $(P>0.05)$. Statistically significant differences were not observed among the other groups $(P>0.05)$. 


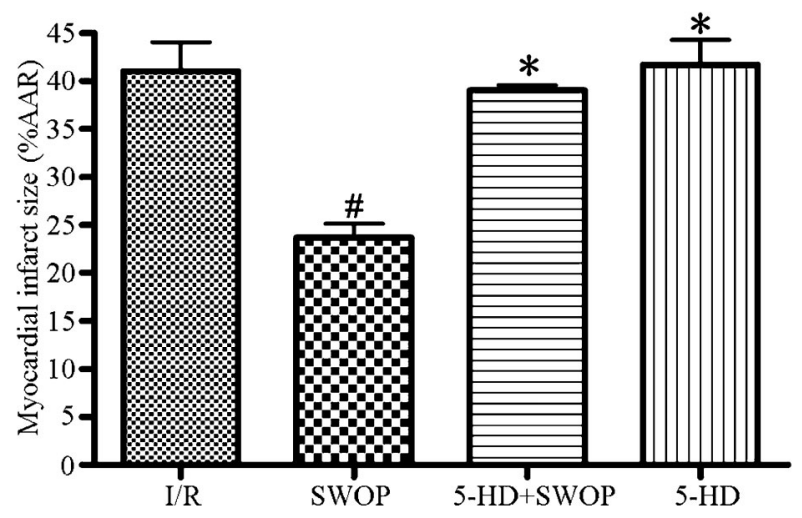

Figure 1. Myocardial infarct size after $2 \mathrm{~h}$ of reperfusion. AAR: area at risk, I/R: ischemia/reperfusion; SWOP: second window of protection; 5-HD: 5-hydroxydecanoate. ${ }^{\#} \mathrm{P}<0.05$ vs I/R group; ${ }^{*} \mathrm{P}<0.05$ vs SWOP group (one-way ANOVA).

The results are shown in Figure 2.

\section{Western blots}

Before development of ischemia, p-PKC- $\varepsilon$ expression was upregulated in the SEVO and SWOP groups compared with the $\mathrm{CON}$ and $\mathrm{I} / \mathrm{R}$ groups $(\mathrm{P}<0.05)$, and p-PKC- $\varepsilon$ was downregulated in the $5-H D+$ SWOP group $(\mathrm{P}<0.05)$ compared with the SWOP group. 5-HD downregulated $\mathrm{p}-\mathrm{PKC}-\varepsilon$ expression, but $5-\mathrm{HD}$ alone did not influence $p-P K C-\varepsilon$ expression compared with expression in the I/R group $(\mathrm{P}>0.05)$. Caspase-8 expression before ischemia did not differ significantly among the other groups $(P>0.05)$. The results are shown in Figures 3 and 4 .

After reperfusion, p-PKC- $\varepsilon$ expression was upregulated in the SEVO group compared with the CON group

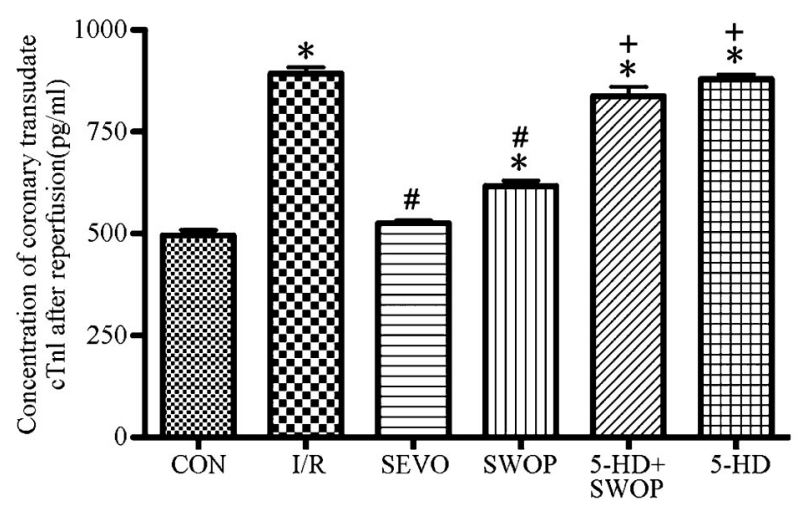

Figure 2. Concentration of coronary transudate cTnl after $2 \mathrm{~h}$ of reperfusion. cTnl: cardiac troponin I; CON: control; I/R: ischemia/ reperfusion; SEVO: sevoflurane; SWOP: second window of protection; 5-HD: 5-hydroxydecanoate. ${ }^{*} \mathrm{P}<0.05$ vs CON group; ${ }^{\#} \mathrm{P}<0.05$ vs $\mathrm{I} / \mathrm{R}$ group; ${ }^{+} \mathrm{P}<0.05$ vs $\mathrm{SWOP}$ group (one-way ANOVA).
$(P<0.05)$, but there were no statistically significant differences in expression among the $\mathrm{I} / \mathrm{R}$, SWOP, and $5-H D+$ SWOP groups $(P>0.05)$. Caspase-8 expression was downregulated during reperfusion in the SWOP group $(\mathrm{P}<0.05)$ compared with the I/R group. Caspase8 expression was upregulated during reperfusion in the $5-H D+$ SWOP group $(P<0.05)$ compared with the SWOP group. 5-HD alone did not influence caspase-8 expression compared with that in the I/R group $(P>0.05)$. The results are shown in Figures 3 and 4.

\section{Discussion}

This study showed that delayed sevoflurane preconditioning reduced myocardial infarct sizes and protected against myocardial ischemia/reperfusion (I/R) injury in isolated rats. The mitoK $\mathrm{K}_{\text {ATP }}$ channel played an important role in triggering the upregulation of $p-P K C-\varepsilon$ as well as the downregulation of the anti-apoptotic protein caspase8 , thereby decreasing the severity of myocardial I/R injury.

APC occurs within a few hours (2-3 $h$ in the early stages) to within a few days before ischemia, reaches a peak in approximately 24 to $48 \mathrm{~h}$ and persists for $72 \mathrm{~h}$ (18). Konia (19) reported that inhalation of $2.5 \%$ sevoflurane for $1 \mathrm{~h}$ reduces $\mathrm{I} / \mathrm{R}$ injury in rats. The results of the blood gas analysis prior to sevoflurane preconditioning confirmed that the rats in this study had normal blood gas concentrations. The transudate cTnl concentrations increased during reperfusion compared with those in the equilibrium phase and their infarct sizes remained within a certain range of difference, which indicated the successful establishment of the Langendorff isolated heart perfusion model.

Sevoflurane is a new inhalational anesthetic that is widely used clinically and has been recommended for routine use during noncardiac surgery for patients with a risk of myocardial infarction. Sevoflurane affects the dynamics of human blood, heart rate, and sympathetic nerve activity, and it has a low blood-gas partition coefficient (0.63). Recovery after discontinuation is rapid, but with respiratory tract irritation. Sevoflurane is highly stable and superior to other anesthetics. Lutz (20) reported that $2.5 \%$ sevoflurane pretreatment before myocardial ischemia significantly improves cardiac function. Chiari et al. (21) reported that intravenous emulsified sevoflurane has both an early and a delayed myocardial protective effect; however, the mechanism of this delayed protective effect is unclear (19).

LVEDP reflects left ventricular compliance, whereas LVSP reflects left ventricular systolic function. LVEDP was decreased, whereas LVDP, LVSP, HR, and $\pm \mathrm{dP}$ / dtmax were increased during reperfusion in the SWOP group compared with those in the I/R group, which suggest that the protective effect of delayed sevoflurane preconditioning significantly improves both diastolic and systolic cardiac function. LVEDP was increased, whereas 

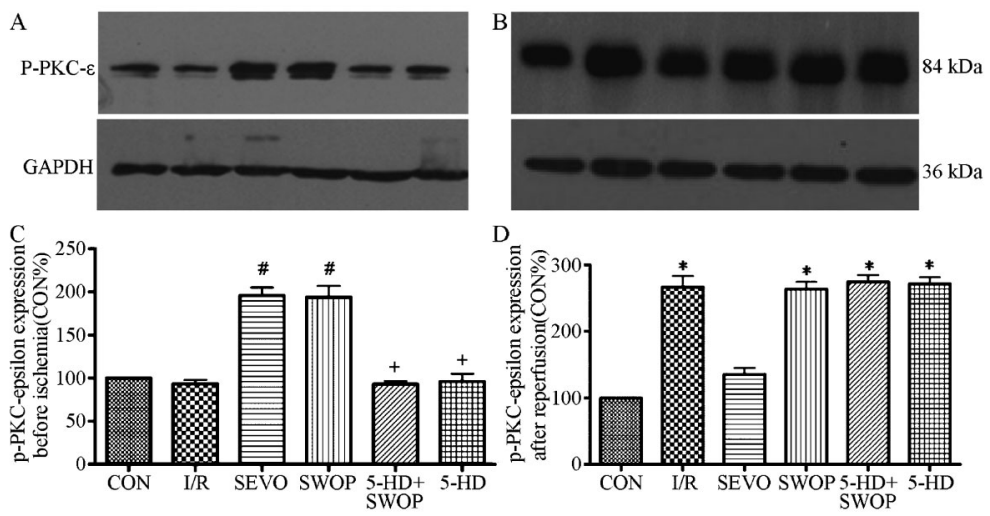

Figure 3. $\mathrm{p}-\mathrm{PKC}-\varepsilon$ expression before ischemia $(A, C)$ and $2 \mathrm{~h}$ after reperfusion $(B, D)$. p-PKC- $\varepsilon$ : phosphorylated protein kinase $C-\varepsilon$; CON: control; I/R: ischemia/reperfusion; SEVO: sevoflurane; SWOP: second window of protection; 5-HD: 5-hydroxydecanoate. ${ }^{*} \mathrm{P}<0.05$ vs CON; ${ }^{\#} \mathrm{P}<0.05$ vs $\mathrm{I} / \mathrm{R}$ group; ${ }^{+} \mathrm{P}<0.05$ vs SWOP group (one-way ANOVA).
LVDP, LVSP, HR, and $\pm \mathrm{dP} / \mathrm{dtmax}$ were decreased during reperfusion in the 5-HD group compared with those in the SWOP group, which suggest that mitoK $\mathrm{ATP}_{\text {is }}$ involved in the protective effect of delayed sevoflurane preconditioning.

Myocardial infarct size is the gold standard for measuring myocardial $\mathrm{I} / \mathrm{R}$ injury. The infarcts in the SWOP group were smaller than those in the $I / R$ group, which indicates that sevoflurane pretreatment has a delayed protective effect against $\mathrm{I} / \mathrm{R}$ injury in isolated perfused rat hearts. The infarcts in the SWOP group were larger than those in the 5-HD+SWOP group, which suggests that mitoK $K_{\text {ATP }}$ is involved in the protective effect of delayed sevoflurane preconditioning.

mitoK $_{\text {ATP }}$ channels are present in the mitochondrial membranes of myocardial cells, and they function during tissue ischemia as hypoxia protection effectors (9). mitoK $_{\text {ATP }}$ channels act as influx rectifier potassium channels activated by intracellular nucleoside diphosphate, whereas intracellular ATP inhibits their opening. Under normal physiological conditions, the $\mathrm{K}_{\mathrm{ATP}}$ channel is closed, but myocardial ischemia, decreased intracellular ATP concentration, and ischemic metabolite accumulation causes membrane hyperpolarization cardiac action potential duration (APD) shortening, calcium currents, and decreased myocardial contractility that trigger the opening of $\mathrm{K}_{\text {ATP }}$ channels. mitoK $\mathrm{K}_{\text {ATP }}$ channels are present in the mitochondrial membrane, and are activated by hypoxia metabolites known as hypoxiainduced effectors to protect tissues from injury. Calcium release reduced apoptosis after ischemia-reperfusion injury (22). Studies have shown that the opening of mito $_{\text {ATP }}$ channels is triggered and/or mediated during the early stages of inhalational anesthetic preconditioning (23-25). In the current study, 5-HD, a specific inhibitor of the mitoK $K_{\text {ATP }}$ channels, weakened the protective effect of sevoflurane, which demonstrates that mitoK $\mathrm{K}_{\text {ATP }}$ channels are involved in the protective effect of sevoflurane. cTnl is a cardiac myocyte-specific marker for myocardial injury that occurs at different concentrations. cTnl is a sensitive indicator of myocardial injury. The concentrations of coronary transudate cTnl were higher, and myocardial infarct sizes were larger, in the 5-HD + SWOP group than in the SWOP group. This result shows that inhibition of mitoK $_{\text {ATP }}$ channels increases the cTnl transudate concentration and the myocardial infarct size. Therefore, mitoK $K_{\text {ATP }}$ channels triggered the protective effect of sevoflurane preconditioning.
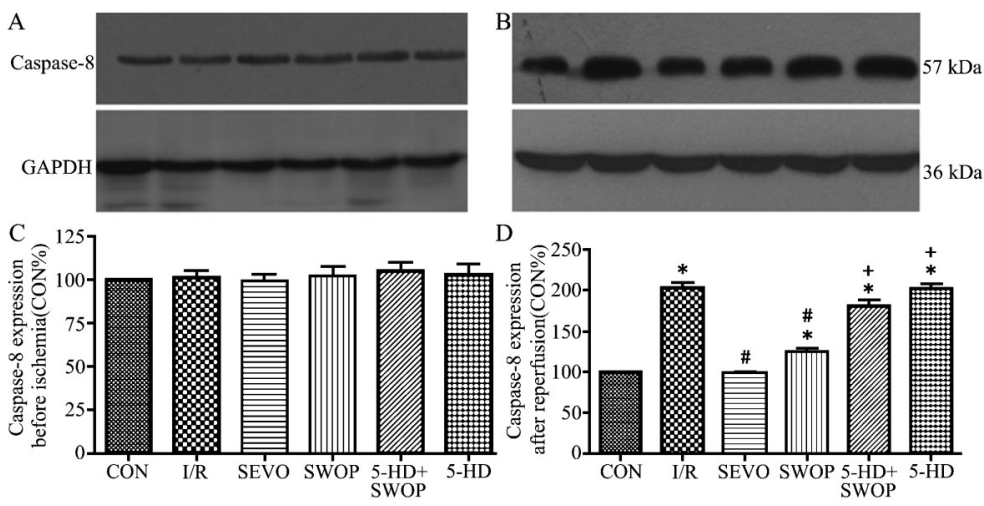

Figure 4. Caspase-8 protein expression before ischemia $(A, C)$ and $2 \mathrm{~h}$ after reperfusion $(B, D)$. CON: control; I/R: ischemia/reperfusion; SEVO: sevoflurane; SWOP: second window of protection; 5-HD: 5-hydroxydecanoate. ${ }^{*} \mathrm{P}<0.05$ vs CON; ${ }^{*} \mathrm{P}<0.05$ vs $\mathrm{I} / \mathrm{R}$ group; ${ }^{+} \mathrm{P}<0.05$ vs SWOP group (one-way ANOVA). 
MitoK $_{\text {ATP }}$ channels mediate the effects of inhaled anesthetic preconditioning by activating $G$ proteincoupled receptors and the intracellular signal transduction pathway, as well as the translocation of PKC- $\varepsilon$ (9). Studies have shown that $G$ protein-coupled receptor agonists such as adenosine, opioids, and bradykinin reduce the cell infarction size range (26). Ischemic and pharmacological preconditioning activates PKC (27), protein tyrosine kinase (PTK) (26), and mitogen-activated protein kinases (MAPK) (28). APC occurs in organs such as the brain, heart, liver, small intestines, skeletal muscles, kidneys, and lungs. The possible mechanisms of APC include glutamate, adenosine receptor activation mechanisms, mitoK $\mathrm{K}_{\mathrm{ATP}}$ channels, nitric oxide, oxidative stress, and low temperature mechanisms. The low temperature mechanisms include those that involve protein kinase $\mathrm{C}$, which is released by a series of signal transduction mechanisms. As a novel protein kinase $\mathrm{C}$, PKC- $\varepsilon$ plays an important role in the development of ischemic tolerance. Myocardial ischemia tolerance is dependent on PKC activation, especially on the activation

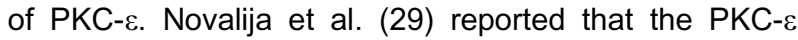
inhibitor PP-149 counteracts the myocardial protective effects of sevoflurane pretreatment in Langendorff models, confirming the role of sevoflurane in PKC- $\varepsilon$-mediated myocardial protection. Weber et al. (30) reported that xenon exerts its myocardial protective effect by increasing $\mathrm{PKC}-\varepsilon$ expression. That effect is blocked by $5-\mathrm{HD}$, which suggests that $\mathrm{PKC}-\varepsilon$ is the downstream target of mitoK $\mathrm{K}_{\mathrm{ATP}}$ channels. The degree of PKC- $\varepsilon$ phosphorylation was lower before myocardial ischemia, which suggests that mitoK $_{\text {ATP }}$ channels trigger the delayed protective effect of sevoflurane by increasing $\mathrm{PKC}-\varepsilon$ phosphorylation.

Myocardial ischemia causes cell necrosis, which delays myocardial apoptosis. Delayed anesthetic preconditioning protects against myocardial infarction by downregulating caspase-3 (31). Apoptosis is gene-controlled autonomous programmed cell death (32) and is regulated by genes and proteins such as Bcl-2, caspase-3, and caspase-8. Caspases are essential in the apoptotic process. Caspase- 8 is usually secreted as a zymogen. Once activated, caspase- 8 causes the cleavage and activation of caspase-3, caspase-6, and caspase-7, resulting in apoptosis (2). Apoptosis is an irreversible cascade of limited substrate hydrolysis of caspases $(33,34)$. Sevoflurane inhibits the production of reactive

\section{References}

1. Kertai MD, Klein J, Bax JJ, Poldermans D. Predicting perioperative cardiac risk. Prog Cardiovasc Dis 2005; 47: 240-257, doi: 10.1016/j.pcad.2005.01.002.

2. Kitagawa $K$, Matsumoto $M$, Tagaya $M$, Hata $R$, Ueda $H$, Niinobe $M$, et al. 'Ischemic tolerance' phenomenon found in the brain. Brain Res 1990; 528: 21-24, doi: 10.1016/00068993(90)90189-I. oxygen species and activates $\mathrm{Bcl}-2$ by stimulating $\mathrm{K}_{\mathrm{ATP}}$ channel opening, thereby preventing apoptosis (35). The pro-apoptotic protein caspase-8 is an upstream promoter that controls the death receptor-mediated apoptosis pathway (36). Considering that 5-HD concentrations were increased before sevoflurane preconditioning, caspase-8 protein expression was elevated during reperfusion. Inhibition of mitoK $\mathrm{K}_{\text {ATP }}$ channels promoted myocardial cell apoptosis. Thus, caspase- 8 is an ideal target for inhibiting apoptosis.

We only used sevoflurane in the current study; thus, we do not know whether all of the volatile anesthetics are equally effective for IPC. A previous study has demonstrated the efficacy of IPC in human surgical series (2). Most of the study focused on the acute phase of protection, not on delayed protection against I/R injury, which occurs 12 to $24 \mathrm{~h}$ after preconditioning. Two types of $\mathrm{K}_{\mathrm{ATP}}$ channels are present in myocardial cells, membrane-bound channels or cell membrane $\mathrm{K}_{\mathrm{ATP}}$ channel (sarcK $\mathrm{K}_{\mathrm{ATP}}$ ) and mitochondrial membrane-bound channels or mitoK $\mathrm{ATP}$. We used only the mitoK $\mathrm{K}_{\mathrm{ATP}}$ channel inhibitor 5-HD in the current study, not the sarcK ATP $_{\text {inhibitor HMR-1098 }}$ because HMR-1098 is not yet commercially available. We did not find any significant difference in the protective effects of the two channels and did not distinguish between the specific mechanisms of the two channels. Finally, we did not investigate the pharmacokinetics and pharmacodynamics of 5-HD and only based the dosage and timing of 5-HD on previously published studies.

In summary, sevoflurane preconditioning exerted a delayed protective effect against myocardial I/R injury in isolated hearts. The mechanism involved mitoK $\mathrm{K}_{\mathrm{ATP}}$ channels, which regulate the phosphorylation of $\mathrm{p}-\mathrm{PKC}$ $\varepsilon$ before ischemia and downregulate caspase-8 during reperfusion.

\section{Acknowledgments}

Research supported by the Natural Science Foundation of Jiangsu Province (grant \#BK20141187 to C. Wang), and by the Technology Bureau of Suzhou, China (grant \#SYS201473 to S.G. Qiao). C. Wang also received support from the Project of Gusu Health Key Talent.

3. Kersten JR, Schmeling TJ, Pagel PS, Gross GJ, Warltier DC. Isoflurane mimics ischemic preconditioning via activation of K(ATP) channels: reduction of myocardial infarct size with an acute memory phase. Anesthesiology 1997; 87: 361-370, doi: 10.1097/00000542-199708000-00024.

4. Engelhard $\mathrm{K}$, Werner $\mathrm{C}$, Reeker $\mathrm{W}$, Lu H, Mollenberg $\mathrm{O}$, Mielke L, et al. Desflurane and isoflurane improve neurological 
outcome after incomplete cerebral ischaemia in rats. $\mathrm{Br} \mathrm{J}$ Anaesth 1999; 83: 415-421, doi: 10.1093/bja/83.3.415.

5. Wang J, Lei B, Popp S, Meng F, Cottrell JE, Kass IS. Sevoflurane immediate preconditioning alters hypoxic membrane potential changes in rat hippocampal slices and improves recovery of CA1 pyramidal cells after hypoxia and global cerebral ischemia. Neuroscience 2007; 145: 1097-1107, doi: 10.1016/j.neuroscience.2006.12.047.

6. Xiong L, Zheng Y, Wu M, Hou L, Zhu Z, Zhang X, et al. Preconditioning with isoflurane produces dose-dependent neuroprotection via activation of adenosine triphosphateregulated potassium channels after focal cerebral ischemia in rats. Anesth Analg 2003; 96: 233-237.

7. De Hert SG, Turani F, Mathur S, Stowe DF. Cardioprotection with volatile anesthetics: mechanisms and clinical implications. Anesth Analg 2005; 100: 1584-1593, doi: 10.1213/01.ANE. 0000153483.61170.0C

8. Fujita A, Kurachi Y. Molecular aspects of ATP-sensitive $\mathrm{K}^{+}$ channels in the cardiovascular system and $\mathrm{K}^{+}$channel openers. Pharmacol Ther 2000; 85: 39-53, doi: 10.1016/ S0163-7258(99)00050-9.

9. Rajapakse N, Shimizu K, Kis B, Snipes J, Lacza Z, Busija D. Activation of mitochondrial ATP-sensitive potassium channels prevents neuronal cell death after ischemia in neonatal rats. Neurosci Lett 2002; 327: 208-212, doi: 10.1016/S03043940(02)00413-5.

10. Hu H, Sato T, Seharaseyon J, Liu Y, Johns DC, O'Rourke B, et al. Pharmacological and histochemical distinctions between molecularly defined sarcolemmal KATP channels and native cardiac mitochondrial KATP channels. Mol Pharmacol 1999; 55: 1000-1005.

11. Papp Z, Csapo K, Pollesello P, Haikala H, Edes I. Pharmacological mechanisms contributing to the clinical efficacy of levosimendan. Cardiovasc Drug Rev 2005; 23: 71-98, doi: 10.1111/j.1527-3466.2005.tb00158.x.

12. Schultz JE, Qian YZ, Gross GJ, Kukreja RC. The ischemiaselective KATP channel antagonist, 5-hydroxydecanoate, blocks ischemic preconditioning in the rat heart. $J$ Mol Cell Cardiol 1997; 29: 1055-1060, doi: 10.1006/jmcc.1996.0358.

13. Ockaili R, Emani VR, Okubo S, Brown M, Krottapalli K, Kukreja RC. Opening of mitochondrial KATP channel induces early and delayed cardioprotective effect: role of nitric oxide. Am J Physiol 1999; 277: H2425-H2434.

14. Garlid KD, Dos Santos P, Xie ZJ, Costa AD, Paucek P. Mitochondrial potassium transport: the role of the mitochondrial ATP-sensitive $\mathrm{K}^{+}$) channel in cardiac function and cardioprotection. Biochim Biophys Acta 2003; 1606: 1-21, doi: 10.1016/S0005-2728(03)00109-9.

15. Li D, Yang C, Chen Y, Tian J, Liu L, Dai Q, et al. Identification of a PKC-epsilon-dependent regulation of myocardial contraction by epicatechin-3-gallate. $A m \mathrm{~J}$ Physiol Heart Circ Physiol 2008; 294: H345-H353, doi: 10.1152/ajpheart.00785.2007.

16. Chen $\mathrm{CH}$, Liu K, Chan JY. Anesthetic preconditioning confers acute cardioprotection via up-regulation of manganese superoxide dismutase and preservation of mitochondrial respiratory enzyme activity. Shock 2008; 29: 300-308.

17. Varadarajan SG, An J, Novalija E, Stowe DF. Sevoflurane before or after ischemia improves contractile and metabolic function while reducing myoplasmic $\mathrm{Ca}\left({ }^{2+}\right)$ loading in intact hearts. Anesthesiology 2002; 96: 125-133, doi: 10.1097| 00000542-200201000-00025.

18. Parra VM, Macho P, Domenech RJ. Late cardiac preconditioning by exercise in dogs is mediated by mitochondrial potassium channels. J Cardiovasc Pharmacol 2010; 56: 268-274, doi: 10.1097/FJC.0b013e3181eb3049.

19. Konia MR, Schaefer S, Liu H. Nuclear factor-[kappa]B inhibition provides additional protection against ischaemia/ reperfusion injury in delayed sevoflurane preconditioning. Eur J Anaesthesiol 2009; 26: 496-503, doi: 10.1097/ EJA.0b013e328324ed2e.

20. Lutz M, Liu H. Inhaled sevoflurane produces better delayed myocardial protection at 48 versus 24 hours after exposure. Anesth Analg 2006; 102: 984-990, doi: 10.1213/01.ane. 0000198568.79079.4c

21. Chiari PC, Pagel PS, Tanaka K, Krolikowski JG, Ludwig LM, Trillo RA Jr, et al. Intravenous emulsified halogenated anesthetics produce acute and delayed preconditioning against myocardial infarction in rabbits. Anesthesiology 2004; 101: 1160-1166, doi: 10.1097/00000542-20041100000016.

22. Pomerantz BJ, Robinson TN, Morrell TD, Heimbach JK, Banerjee A, Harken AH. Selective mitochondrial adenosine triphosphate-sensitive potassium channel activation is sufficient to precondition human myocardium. $J$ Thorac Cardiovasc Surg 2000; 120: 387-392, doi: 10.1067/mtc.2000. 107521.

23. Wang S, Cone J, Liu Y. Dual roles of mitochondrial K(ATP) channels in diazoxide-mediated protection in isolated rabbit hearts. Am J Physiol Heart Circ Physiol 2001; 280: H246$\mathrm{H} 255$.

24. Wang $Y$, Takashi E, Xu M, Ayub A, Ashraf M. Downregulation of protein kinase $C$ inhibits activation of mitochondrial K(ATP) channels by diazoxide. Circulation 2001; 104: 85-90, doi: 10.1161/01.CIR.104.1.85.

25. Yao Z, McPherson BC, Liu H, Shao Z, Li C, Qin Y, et al. Signal transduction of flumazenil-induced preconditioning in myocytes. Am J Physiol Heart Circ Physiol 2001; 280: $\mathrm{H} 1249-\mathrm{H} 1255$.

26. Krieg T, Qin Q, Mclntosh EC, Cohen MV, Downey JM. ACh and adenosine activate PI3-kinase in rabbit hearts through transactivation of receptor tyrosine kinases. Am J Physiol Heart Circ Physiol 2002; 283: H2322-H2330.

27. Fryer RM, Wang $\mathrm{Y}$, Hsu AK, Gross GJ. Essential activation of PKC-delta in opioid-initiated cardioprotection. Am J Physiol Heart Circ Physiol 2001; 280: H1346$\mathrm{H} 1353$.

28. Fryer RM, Hsu AK, Gross GJ. ERK and p38 MAP kinase activation are components of opioid-induced delayed cardioprotection. Basic Res Cardiol 2001; 96: 136-142, doi: $10.1007 / \mathrm{s} 003950170063$.

29. Novalija E, Kevin LG, Camara AK, Bosnjak ZJ, Kampine JP, Stowe DF. Reactive oxygen species precede the epsilon isoform of protein kinase $\mathrm{C}$ in the anesthetic preconditioning signaling cascade. Anesthesiology 2003; 99: 421-428, doi: 10.1097/00000542-200308000-00024.

30. Weber NC, Toma O, Damla H, Wolter JI, Schlack W, Preckel B. Upstream signaling of protein kinase C-epsilon in xenon-induced pharmacological preconditioning. Implication of mitochondrial adenosine triphosphate dependent potassium channels and phosphatidylinositol-dependent 
kinase-1. Eur J Pharmacol 2006; 539: 1-9, doi: 10.1016/ j.ejphar.2006.03.054.

31. Qiao S, Xie H, Wang C, Wu X, Liu H, Liu C. Delayed anesthetic preconditioning protects against myocardial infarction via activation of nuclear factor-kappaB and upregulation of autophagy. J Anesth 2013; 27: 251-260, doi: 10.1007/s00540-012-1494-3

32. Harvey NL, Kumar S. The role of caspases in apoptosis. Adv Biochem Eng Biotechnol 1998; 62: 107-128.

33. Gurtl B, Kratky D, Guelly C, Zhang L, Gorkiewicz G, Das SK, et al. Apoptosis and fibrosis are early features of heart failure in an animal model of metabolic cardiomyopathy. Int J Exp Pathol 2009; 90: 338-346, doi: 10.1111/j.13652613.2009.00647.x.
34. Kuethe F, Sigusch HH, Bornstein SR, Hilbig K, Kamvissi V, Figulla HR. Apoptosis in patients with dilated cardiomyopathy and diabetes: a feature of diabetic cardiomyopathy? Horm Metab Res 2007; 39: 672-676, doi: 10.1055/s-2007985823.

35. Lu X, Liu H, Wang L, Schaefer S. Activation of NF-kappaB is a critical element in the antiapoptotic effect of anesthetic preconditioning. Am J Physiol Heart Circ Physiol 2009; 296: H1296-H1304, doi: 10.1152/ajpheart.01282.2008.

36. Gervais FG, Singaraja R, Xanthoudakis S, Gutekunst CA, Leavitt BR, Metzler M, et al. Recruitment and activation of caspase- 8 by the Huntingtin-interacting protein Hip-1 and a novel partner Hippi. Nat Cell Biol 2002; 4: 95-105, doi: 10.1038/ncb735. 